\title{
CORRIGENDA
}

\section{CORRIGENDUM: 4-1BB-mediated immunotherapy of rheumatoid arthritis}

Su K Seo, Jae H Choi, Young H Kim, Woo J Kang, Hye Y Park, Jae H Suh, Beom K Choi, Dass S Vinay \& Byoung S Kwon Nat. Med. 10, 1088-1094

In the Figure 4 legend, "CD11 $\mathrm{c}^{+} \mathrm{CD} 8^{+} \mathrm{T}$ or $\mathrm{CD} 11 \mathrm{c}^{-} \mathrm{CD} 8^{+}$" should read "CD11c $\mathrm{c}^{+} \mathrm{CD} 8^{+}$or $\mathrm{CD} 11 \mathrm{c}^{-} \mathrm{CD} 8^{+} \mathrm{T}$ cells."

In $\mathbf{b}$ of the Figure 5 legend, "control IgG or" should be deleted. 